\title{
Research of the Learner-Centered Teaching Model for Distance Education
}

\author{
Guo Hongliang ${ }^{1, a}$ Kong Shaoying ${ }^{2, a}$ Liu Wei ${ }^{2, a}$ \\ ${ }^{1}$ JiLin Agricultural University,Changchun, China \\ ${ }^{2}$ JiLin Radio and TV University, Changchun, China \\ ${ }^{2}$ JiLin Radio and TV University,Changchun, China \\ ${ }^{a}$ kongsy@jlrtvu.jl.cn
}

Keywords: Distance Education; Task-driven; Learning-Assistance; Learning-Guide; Learning-Promotion

\begin{abstract}
Compared with the traditional education, the advantages represented by the distance education are discussed in this paper. Based on the analysis on the existing problems in the teaching process of the distance education, the leaner-centered teaching model is proposed and the "task-driven" teaching system is constructed to improve the effectiveness of teaching in the distance education.
\end{abstract}

With the development of modern information and technologies, the distance education is propos ed as one of the newly proposed educational methodology. As a kind of advanced life-long le arning method, the distance education focuses on the learners. Those, who have no access to $t$ he college because of restriction of time and space, are provided with new way of education $b$ $\mathrm{y}$ theapplication of multi-media and communication methods ${ }^{[1][2][3]}$.

\section{Main problems in teaching process of current distance education}

Since the distance education is learner-centered, we have to create the environment suitable for learners, to comprehend the contents, we need to cultivate learning ability and break the time-space limitation to carry out the learning activity accordingly. The teachers are supposed to provide students with good environment that can lead, help and stimulate the learners to study. Thus, the problems rooted in the process of the distance education should be carefully analyzed.

\section{A. distance education is not "distant"}

The time-space limitation is not totally destroyed in some extent and distance education can even be treated as the updated version of the traditional education. The state of "permanent departure" is not realized and the students have to come to schools periodically to take part in all kinds of teaching activities, especially most classes are evaluated based on the final examination. Therefore, the distance education could never relived the learners from contradiction between learning and working, but burden them with too much workload.

\section{B. The deficiency of autonomous learning ability is not improved}

Firstly, the learners are almost unconscious when choosing the distance education and lack the knowledge about the learner-centered distance education model. Secondly, they do not have comprehensive understanding about the learning ability and custom in former education. The learners would feel confused when come to the new period and incapable of teaching themselves by using resources reasonably. Finally, the learning motive is mainly originated from external environment and the motive originated from the requirement of the modern times is very weak ${ }^{[4][5][6]}$.

C. Role transformation is far from achieving in distance education 
In distance education, it should be learner-centered and teacher-guided. The dominance and authority of teachers in traditional education should be changed. But actually, some teachers still rely on their specific teaching methods, organization and style. The situation can not be changed in short period, and thus some teachers are not qualified for new teaching model for the lack of information skills.

\section{The awkward situation of learning resources}

The resources, that provide a platform to demonstrate the teacher's ability and provide strong guarantee of teaching quality, are directly received by learners in the process of the distance education. However, the awkward situation between teaching and learning can not be neglected. On one hand, the learning resources are tedious and cannot satisfy the requirement of learners. The learners are totally lost when faced with such great online information. On the other hand, the resources, produced by teachers with great energy, manpower and money, are never visited by learners. This may frustrate the teachers greatly. Besides, the teachers are playing "solo" in timely or non-timely teaching process where resources are updated dynamically.

\section{E. Missing of personalized services}

The distance education aims at autonomous learning and teaching in accordance with learner's personalities to satisfy the learners with what they need. But in fact, the situation is very much alike that in the traditional education. Such as the contents and difficulties of the same course are exactly the same, even the time and place of the examination are also the same. This is contradictory to the principle of the distance education and to become an important way of evaluating the quality of the distance education. Obviously, it is incapable of helping the learners and cultivating them to be useful to our society.

\section{The development of the "task-driven" system for distance education}

Based on the analysis to the problems in the teaching process of the distance education, we establish a team entitled "The development of the task-driven system for distance education" with the aim for developing a learner-centered task-driven system to optimize the teaching process of the distance education. The system not only shows the dominant place of the learner in the process of the distance education, but also grants teachers with the role of leading. The system would enhance the learning ability and practical working ability, and it would further improve their ability in analyzing and resolving problems to cultivate more people with high intelligence and skills.

As is discussed in constructivism theory, the knowledge is actively constructed within certain context with the help of teachers and necessary resources. The core part of this project is the realization of the active learning with the help of teachers. The learners are active constructors while teachers play the role of supervisor, stimulator and tutor in constructing the knowledge. Consequently, this project is learner-centered, with the highlight of their activity and the role of context in meaning construction. Based on this theory, the learner-centered "task-driven" distance education system is proposed, combined with the practical situation in the distance education.

The system can be divided into three subsystems:

\section{A. The bilateral learning assistance subsystem}

Figure 1: 


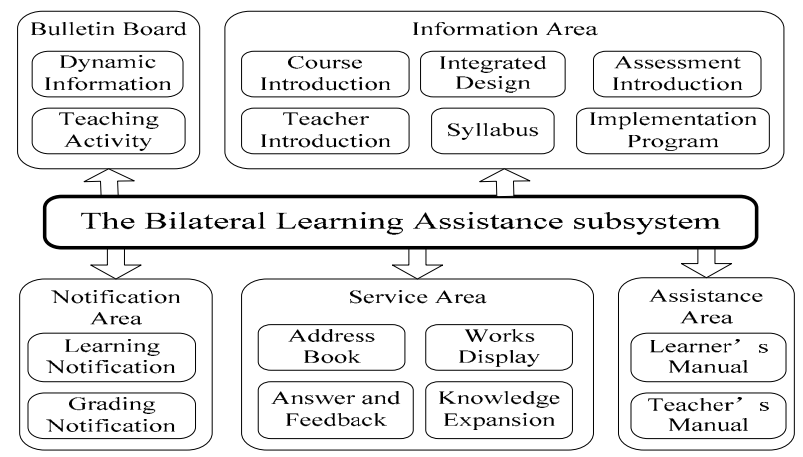

As shown in figure 1, the bilateral learning assistance subsystem is useful in providing the learners with the help of learning actively while providing the teachers with a platform. The bulletin board includes the contents about the updating of learning resources, timely and non-timely teaching activities and so on. The notification area is divided into the control to the autonomous learning progress and the notification for the teachers to grade. The information area provides teaching resources, such as the course introduction, teacher introduction, integrated design, assessment introduction, syllabus and implementation program and so on. The assistance area gives a detailed explanation about the use of the system for teachers and students. The service area provides teachers and students with a platform to communicate. The answer and feedback can be timely or non-timely to realize a kind of virtual communication.

\section{B. The orientated learning guide subsystem}

Figure 2:

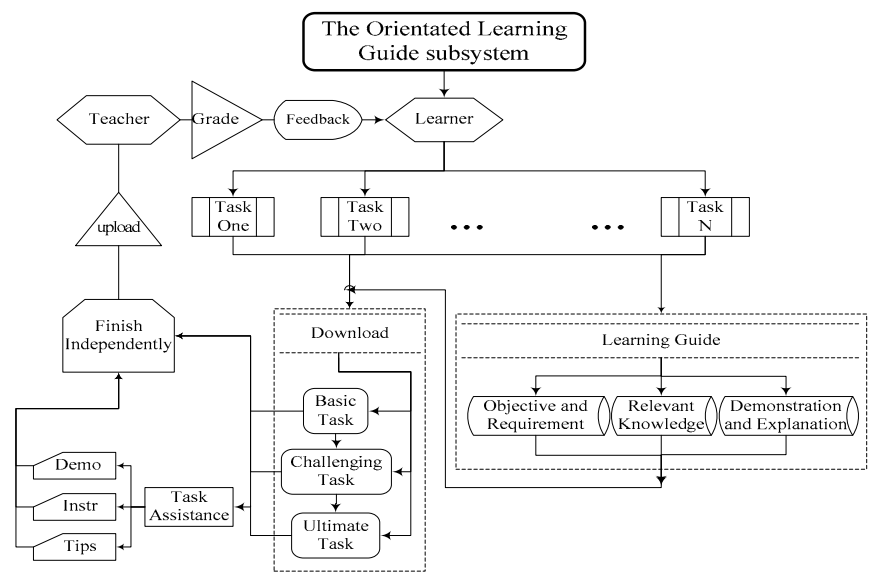

The learning platform provided by one task is shown in figure 2. There may be multiple tasks designed based on different courses. But the basic forms are consistent. The task-driven teaching model is built on the teaching model of the constructivism teaching theory. The learners' subjectivity and autonomous learning ability are highlighted. The teachers are responsible for giving careful consideration to each learner's personality, analyzing the teaching contents, presenting the knowledge points and expected objectives in the form of task and stimulating the autonomous learning motivation and learning desire by means of task. The learners are supervised by teachers and driven by task. The learning is assisted with different kinds of multi-media to facilitate the learners to study actively, cooperated with each other. The aim of knowledge comprehension is achieved by accomplishing the predefined tasks. The ability of thinking independently and resolving the problem is also cultivated at the same time. In task-driven teaching model, the task is the core subject of the both teaching and learning. The whole teaching activities focuses on how the tasks can be carried out. Based on the personal learning status, the students can choose the corresponding tasks and finish them independently. In the process of 
finishing certain task, they can get help by means of demonstration, instruction and learning tips. The learning guide provides detailed instruction about the contents related to one task, including the objective and requirement, static relevant knowledge and dynamic demonstration.

\section{The Assessing learning promotion subsystem}

Figure 3:

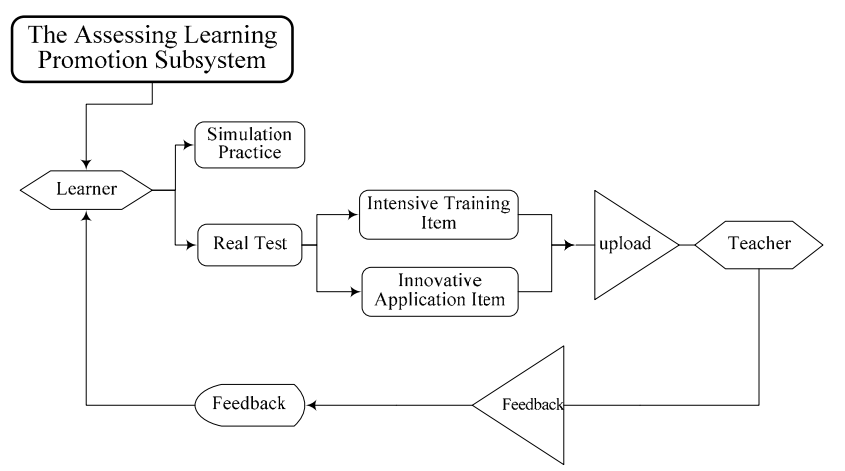

After finishing the previous tasks and arriving to a certain extent, it is allowed to enter into the Assessing learning promotion subsystem. In this subsystem, the simulated practice and real test are provided in order to make sure that the new environment wouldn't prevent the learners from performing excellently.

It is obvious to see that the real time tracking in the backstage of the learner-centered task-driven distance education system is able to give real time evaluation and timely evaluation to activities of both teachers and students including the contents and format of the learning resources, the learners' autonomous learning process and strategies and its effect, the teaching strategies design of assistance, guide and promotion. This may help supervise the process of both learning and teaching. The system can be adjusted timely to fit the learner-centered task-driven distance education system and to make it more humanized, scientific and effective.

\section{ACKNOWLEDGMENT}

This paper was supported by 2012 Annual Research Project of National Open University with the proje ct number of Q0902A-S.

\section{REFERENCES}

[1] France, Belanger, Dianne H. Jordan. Evaluation and Implementation of Distance Learning T echnologies, Tools and Techniques. Ershey: Idea Group Publishing,2000:8-20

[2] Zimmerma B J. Becoming A Self-Regulated Learning. Theory in Practice, 2002, 41(3):64-6 7

[3] Paris. Classroom Application of Research on Self-Regulated Learning. Educational Psycholo gist.2001,36(3):89-113

[4] Lorraine Smith. Changes in Student Motivation over the Final Year of High School. Journ al of Educational Enquiry,2004,5(2):64-83

[5] He Kekang, Lin Junfen, Zhang Wenlan. Instructional System Design. Higher Education Pre ss, 2006:66

[6] Alan Tait. Planning Student Support for Open and Distance Learning. Open Learning,2000, 167(3):65-68 